\title{
DESAIN KOMPONEN PEMIPIL JAGUNG PADA MESIN PERONTOK PAJAKA (Padi, Jagung, Kacang)
}

\author{
Max Kurniawan $^{1)}$, Moh.Fikri Pomalingo ${ }^{2)}$, Agus Susanto Ginting ${ }^{2)}$ \\ ${ }^{1)}$ Mahasiswa Politeknik Gorontalo, Kampus Puncak Desa Panggulo Bone Bolango \\ ${ }^{2)}$ Tim Pengajar pada Program Studi Mesin dan Peralatan Pertanian, Politeknik Gorontalo
}

\begin{abstract}
ABSTRAK
Jagung merupakan komoditas tanaman pangan yang banyak dibudidayakan petani. Jagung juga merupakan bahan pangan pokok kedua setelah beras bagi masyarakat Gorontalo. Hampir semua bagian tanaman jagung mempunyai kegunaan. Batang dan daun jagung dapat digunakan untuk kertas dan papan dinding. Tongkol dapat digunakan untuk bahan bakar, silosa dan furfural. Tujuan dari penelitian ini adalah Merancang komponen pemipil berbentuk poros bergerigi dan menguji kinerja poros pemipil dengan memanfaatkan putaran mesin penggerak. Mesin ini memiliki manfaat antara lain: Dapat mempercepat proses pemipilan dari yang dilakukan secara manual dan mempermudah petani dalam memipil jagung serta meningkatkan pendapatan mereka. Prinsip kerja mesin pemipil ini digerakkan oleh motor penggerak, daya dari penggerak ditransmisikan oleh puli dan v-belt keporos pemipil. Untuk melakukan pemipilan, dengan memanfaatkan putaran jagung diletakkan pada poros pemipil sehingga jagung tesebut akan terpipil dengan sendirinya karena ban karet yang ada pada poros berfungsi sebagai perontok. Hasil uji coba menggunakan sampel $1 \mathrm{~kg}$ jagung pada tiap putaran. Percobaan pertama yaitu pada putaran $1200 \mathrm{Rpm}$ mendapatkan $308.46 \mathrm{~g} /$ menit, percobaan kedua yaitu pada putaran $1400 \mathrm{Rpm}$ mendapatkan $302.35 \mathrm{~g} /$ menit dan percobaan ketiga yaitu pada putaran 1600 Rpm mendapatkan $212.12 \mathrm{~g} /$ menit.
\end{abstract}

Kata kunci : Poros Pemipil, Putaran, Mesin Penggerak

\section{DESIGN OF CORN PROCESSING COMPONENTS IN SHOPPING MACHINES RICE, CORN, PEANUTS}

\begin{abstract}
Corn is a commodity of food crops that many farmers cultivate. Corn is also the second major foodstuff after rice for the people of Gorontalo. Almost all parts of corn are useful. Stems and corn leaves can be used for papers and wall boards. Cylinders can be used for fuel, silos and furfural. The purpose of this study is Designing a shaft-shaped shaft shaft component and testing the performance of the shaft shaft by utility the rotation of the engine. This machine has the following benefits: It can speed up the process of filling from manually and facilitating farmers in corn harvesting and increasing their income. The working principle of the machine is driven by the drive motor, the power of the actuator is transmitted by the pulley and v-belt slabs. To do the trimming using the corn rotation is placed on the shaft of the slag, so that the corn will be blown by itself. The rubber tire on the shaft serves as a threshing. Test results using a $1 \mathrm{~kg}$ sample of corn in each spin. The first experiment was at $1200 \mathrm{rpm}$ to get $308.46 \mathrm{gr} /$ minute, the second experiment was 1400 rpm Rpm to get $302.35 \mathrm{gr} /$ minute and the third attempt was $162 \mathrm{rpm} 212.12 \mathrm{gr} / \mathrm{minute}$.
\end{abstract}

Key words : Shaft, Shaft, Engine. 


\section{PENDAHULUAN}

Jagung merupakan komoditas tanaman pangan yang banyak dibudidayakan petani. Jagung juga merupakan bahan pangan pokok kedua setelah beras bagi masyarakat Gorontalo. Pemanfaatan jagung selain sebagai bahan subtitusi beras juga dapat digunakan untuk pakan ternak dan bahan baku industri. Penggunaan jagung sebagai bahan baku industri pertanian lebih luas dari beras.

Hampir semua bagian tanaman jagung mempunyai kegunaan. Batang dan daun jagung dapat digunakan untuk kertas dan papan dinding. Tongkol dapat digunakan untuk bahan bakar, silosa dan furfural, sedangkan biji jagung dapat diolah menjadi bahan makanan

Salah satu provinsi di Indonesia yang memproduksi jagung sebagai tanaman pangan utama adalah Provinsi Gorontalo. Gorontalo merupakan salah satu provinsi dengan komoditas unggulan tanaman jagung. Luas panen tanaman ini pada tahun 2015 sekitar 129.131 ha dengan produksi mencapai 643.512 ton.

Pada masyarakat Gorontalo sendiri dari proses penanaman, sampai proses pasca panen masih menggunakan cara manual dan tradisional salah satu contoh penanganan jagung yang masih tradisional adalah pemipilan. Pemipilan merupakan proses pemisahan bongkol dengan biji jagung. Proses pemipilan ini pada umumnya dilakukan oleh petani jagung secara manual dengan menggunakan tangan. Pemipilan menggunakan tangan hanya menghasilkan pipilan dengan jumlah yang sedikit dikarenakan petani mengalami kelelahan dan meyebabkan rasa sakit pada tangan saat mereka melakukan pemipilan.

Selain pemipilan secara manual, masyarakat Gorontalo juga menggunakan mesin pemipil untuk proses pemipilan, hanya saja di beberapa tempat di provinsi Gorontalo mesin pemipil ini sangat jarang digunakan, hal ini disebabkan harga peminjam mesin tersebut sangat mahal dan juga untuk mobilisasi mesin ini sangat sulit untuk mencapai lokasi yang berada di pegunungan dikarenakan ukuran mesin yang besar sehingga untuk mengangkatnya butuh banyak orang.

Berdasarkan masalah tersebut, maka penulis akan mendesain mesin pemipil jagung yang portable untuk mempermudah petani di Provinsi Gorontalo. Keunggulan mesin yaitu petani tidak mengalami kelelahan dan keluhan sakit pada jari tangan, serta tidak memakan waktu lama saat pemipilan, seperti halnya proses pemipilan manual yang saat ini sering mereka lakukan.

\section{TINJAUAN PUSTAKA}

\section{Karakteristik Fisik Jagung}

Pada jagung yang memiliki ciri-ciri siap untuk dipipil yaitu kelobot berwarna kuning, biji sudah tua dan berwarna mengkilap pada butiran jagung sudah berbentuk jaringan tertutup bewarna hitam, dan bila biji jagung tersebut ditekan dengan kuku tangan maka pada bagian jagung tidak akan membekas, pada kondisi ini perkiraan kandungan air sudah $35 \%$.

Setelah dipanen jagung agar dibuka sehingga kadar air pada tongkol menurun dan terhindar dari serangan jamur. Pengeringan tonggkol hingga kadar air 17- 20\% agar mudah dipipil dan segera dijemur sampai kadar air 15\% proses ini untuk memudah petani saat melakukan pemipilan secara manual menggunakan tangan atau dengan menggunakan mesin.

\section{Jenis-Jenis Pimipil Jagung Secara Manual}

Pemipilan secara manual mempunyai beberapa keuntungan, antara lain persentase biji rendah dan sedikit kotoran yang tercampur dalam biji. Kapaasitas pemipilannya sangat rendah yaitu 10-20 kg/jam/orang, sehingga dibutuhkan waktu 8,33 hari untuk memipil satu ton jagung. Lamanya waktu pemipilan menyebabkan penundaan proses selanjutnya, sehingga mempercepat berkembangnya aflatoksin.

Pemipilan jagung dengan tenaga manusia dapat dilakukan dengan tangan, tongkat pemukul, gosrokan, pemipil besi diputar, pemipil besi bergerigi dan alat pemipil jagung sederhana lainnya. Pemipilan jagung dengan tenaga manusia sebaiknya dilakukan pada tingkat kadar air 17\% . (A'ayuni, 2017)

\section{Secara Mekanis}

Pemipilan secara mekanis yaitu dengan menggunakan mesin pemipil jagung (corn sheller). Keuntungan dari penggunaan mesin adalah kapasitas pemipilan lebih besar dari cara manual. Namun apabila cara pengoperasiannya tidak benar dan kadar air jagung yang di pipil tidak sesuai, maka akan mempengaruhi viabilitas benih. Mesin pemipil jagung telah banyak dihasilkan dan dikenal masyarakat namun banyak menghasilkan jagung pipil utnuk bahan baku pakan maupun pangan.

Pemipilan dengan tenaga mekanis umumnya dilakukan oleh petani pada pusat-pusat produksi 
jagung, dengan cara menyewa mesin pemipil tersebut. Yang perlu diperhatikan adalah mesin pemipil jagung dengan konstruksi gigi khusus sehingga dapat digunakan untuk pemipilan jagung pada kadar air sekitar 35\%. Mesin pemipil model ini bekerja di daerah produksi jagung yang menghasilkan jagung pipil dengan mutu yang baik dan biaya yang rendah bagi petani. (A'ayuni, 2017)

\section{METODE PENELITIAN}

\section{Perancangan Fungsional}

Perancangan fungsional merupakan fungsi dari setiap komponen mesin yang akan di rancang dan dibuat. Komponen-komponen mesin pemipil jagung antara lain terdapat pada tabel berikut.

Tabel 1. Fungsi setiap komponen pada mesin pemipil jagung

\begin{tabular}{|c|c|c|}
\hline No & Fungsi Utama & Komponen \\
\hline 1 & $\begin{array}{l}\text { Landasan untuk } \\
\text { semua komponen- } \\
\text { komponen mesin. }\end{array}$ & Rangka Mesin \\
\hline 2 & $\begin{array}{l}\text { Sebagai pemipil } \\
\text { jagung dengan } \\
\text { memanfaatkan } \\
\text { putaran }\end{array}$ & $\begin{array}{c}\text { Poros Pemipil } \\
\text { Ban Karet }\end{array}$ \\
\hline 3 & $\begin{array}{l}\text { Untuk menutup bagian } \\
\text { luar dari mesin pengupas } \\
\text { dan pemipil } \\
\text { jagung. }\end{array}$ & Bodi Mesin \\
\hline 4 & $\begin{array}{lc}\begin{array}{l}\text { Sebagai } \\
\text { tenaga }\end{array} \quad \begin{array}{c}\text { sumber } \\
\text { untuk }\end{array} \\
\text { menjalankan mesin } \\
\text { pemipil } \\
\text { jagung dengan } \\
\text { daya } 5.5 \mathrm{Hp} \text {. }\end{array}$ & Motor Bensin \\
\hline 6 & $\begin{array}{l}\text { Sebagai tempat keluar } \\
\text { jagung yang sudah } \\
\text { terkupas, terpipil dan } \\
\text { sudah } \\
\text { bersih }\end{array}$ & Hoper Output \\
\hline 7 & $\begin{array}{l}\text { Untuk } \\
\text { mentransmisikan daya } \\
\text { dari } \\
\text { penggerak }\end{array}$ & Puli dan V-belt \\
\hline
\end{tabular}

\section{HASIL DAN PEMBAHASAN}

Kinerja Kapasitas Mesin

Uji coba alat dilakukan selama 9 kali percobaan dan di bagi menjadi 3 putaran. Pada putaran pertaman kecepatan putaran poros sebesar $1200 \mathrm{rpm}$, putaran kedua kecepatan putaran sebesar $1400 \mathrm{rpm}$ dan putaran untuk ketiga putaran poros sebesar 1600 rpm, sementara untuk jumlah jagung dalam setiap sampel sebanyak $1 \mathrm{~kg}$ atau 1000 gram. Berikut tabel hasil percobaan.

1. Percobaan pada putaran poros $1200 \mathrm{rpm}$ Ket : Menghitung Kapasitas

$$
K K=\frac{\text { Berat Sampel }(\mathrm{kg})}{\text { Waktu (Jom) }}
$$

(Setyaji, 2017)

$$
\mathrm{KK}=308.46 \mathrm{~g} / \mathrm{m}
$$

Jadi untuk pemipilan menggunakan putaran 1200 rpm mendapatkan $308.46 \mathrm{~g} /$ menit

2. Percobaan pada putaran poros $1400 \mathrm{rpm}$ Ket : Menghitung Kapasitas

$$
\mathrm{KK}=302.35 \mathrm{~g} / \mathrm{m}
$$

Jadi untuk pemipilan menggunakan putaran 1400 rpm mendapatkan $302.35 \mathrm{~g} /$ menit

\section{Percobaan pada putaran poros $1600 \mathrm{rpm}$} $\mathrm{KK}=212.12 \mathrm{~g} / \mathrm{m}$

Jadi untuk pemipilan menggunakan putaran 1600 $\mathrm{rpm}$ mendapatkan $212.12 \mathrm{~g} / \mathrm{m}$. . Hal ini dapat dilihat pada grafik antara hubungan putaran poros dan waktu pemipilan serta grafik hubungan antara putaran poros dan berat hasil pipilan.

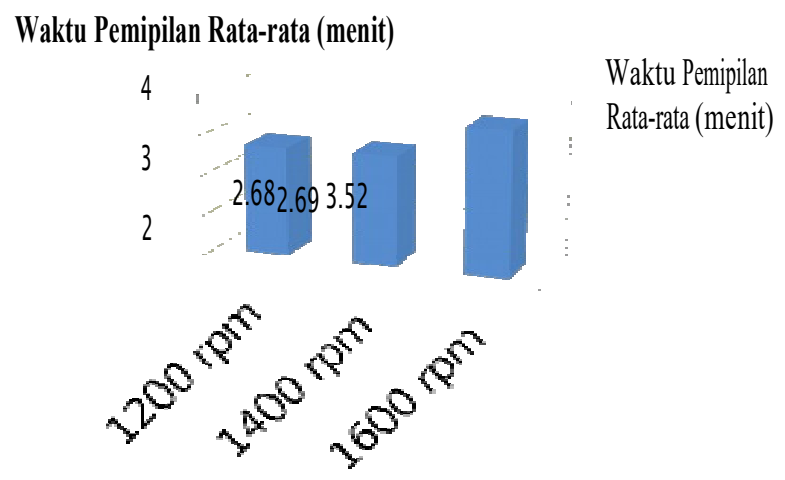

Gambar 1. Grafik Hubungan antara waktu pemipilan dan putaran pada poros 


\section{KESIMPULAN DAN SARAN}

\section{Kesimpulan}

1. Lebih tinggi Rpm yang digunakan. Maka semakin cepat pula proses pemipilan

2. Semakin tinggi Rpm yang digunakan maka kapasitas pemipilan yang dihasilkan semakin rendah

3. Sementara pemipilan yang dilakukan secara manual waktu yang diperoleh untuk $1 \mathrm{~kg}$ jagung perorang membutuhkan waktu rata-rata 42.99 menit $/ \mathrm{kg}$

4. Pemipilan dengan putaran cepat tongkol jagung akan mudah terpotong dan biji jagung akan berhamburan

\section{Saran}

Untuk mendapatkan hasil yang sesui kiranya putaran pada mesin penggerak harus direndahkan agar jagung terpipil dengan baik dan saat pengoperasian haruslah di utamakan keselamatan

\section{DAFTAR PUSTAKA}

A'ayuni, Q. 2017. (2017). Mesin Pemil Jagung dan Alat Pemipil Tradisional. Program Studi Agroteknologi, Fakultas Pertanian, Universitas Muhammadiyah Gresik.

Setyaji, M. A. L. 2017. (2017). Perencanaan dan Perhitungan Mesin Pemipil Jagung dengan Kapastas 300 Kg/Jam. Artikel Skripsi. Program Studi Teknik Mesin, Fakultas Teknik, Universitas Nusantara PGRI Kediri. 